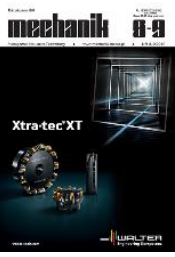

How to cite this article:

Author: Klaudiusz Ziemek

Title of article: "Tower crane simulator for innovative training system using virtual reality environment"

Mechanik, No. 8-9 (2019)

DOI: https://doi.org/10.17814/mechanik.2019.8-9.72

\title{
Tower crane simulator for innovative training system using virtual reality environment
}

\section{KLAUDIUSZ ZIEMEK *}

Mgr Klaudiusz Ziemek, klazie@ciop.pl, https://orcid.org/0000-0003-0346-0304 - Centralny Instytut Ochrony Pracy - Państwowy Instytut Badawczy, Warszawa, Polska

In terms of this paper we are presenting a prototype version of the tower crane simulator being under development in Virtual Reality Department of The Central Institute of Labour Protection in Warsaw. Main purpose of this research is to provide safe and reliable practice tool for tower crane operators with most recent virtual reality technology to improve effectiveness of the training process.

KEYWORDS: simulator, simulation, tower crane, operator training

\section{Introduction}

Tower cranes belong to the group of handling equipment that significantly facilitates the transfer of large and heavy loads on the construction site. The use of tower cranes greatly accelerates construction works, however, it also involves additional risk and generates new scenarios of accidents at work.

The most common causes of accidents involving tower cranes include [1]:

- assembly, disassembly and modification of the crane structure,

- extreme weather conditions,

- usage errors,

- damage to the machine,

- incorrect foundation structure,

- contact with power lines.

Misuse of tower cranes is a serious threat to workers and construction elements, as well as people and other buildings nearby. For this reason, the appropriate methodology and effectiveness of operator training process are very important. Currently, operators gain experience on a real machine immediately after the theoretical course, without any chance to practice in secure and isolated environment. This solution means that the operator is put in a position that precludes any mistake from the very beginning, thus making his knowledge of the subject purely theoretical.

Therefore, we propose a device that will enable tower crane operators to practice various situations of the correct and incorrect functioning of these machines during their training. Such a system should increase the staff qualifications and reduce the risk of accidents at work involving tower cranes.

\section{Tower crane simulator prototype}

The proposed prototype of the tower crane simulator consists of two basic components: a virtual environment and a mechanical platform. Operator interacts with the simulator via the user interface, which is the main subject of research within the project discussed here. Comparison of different interaction models with the simulator will be the basis for assessing the usability and correctness of the device's functioning.

\section{Virtual environment}

Virtual environment operates with the Unity game engine, using graphic models that have been developed in the Blender 3D application. The virtual environment includes: graphic representation of the construction site and town, processes that are responsible for the similarity of the work of the real and simulated crane running in the background, as well as processes recording and assessing the abilities of the trainee. 
The virtual construction site (fig. 1) reflects the structure of the real site. There are:

- construction machinery (cranes, excavators, trucks),

- constructions under construction (residential buildings, foundations),

- employee flats,

- structural elements (pipes, bricks, cable reels, etc.),

- supporting devices (concrete mixers),

- lighting elements (floor and portable lamps),

- security (gates, fences).

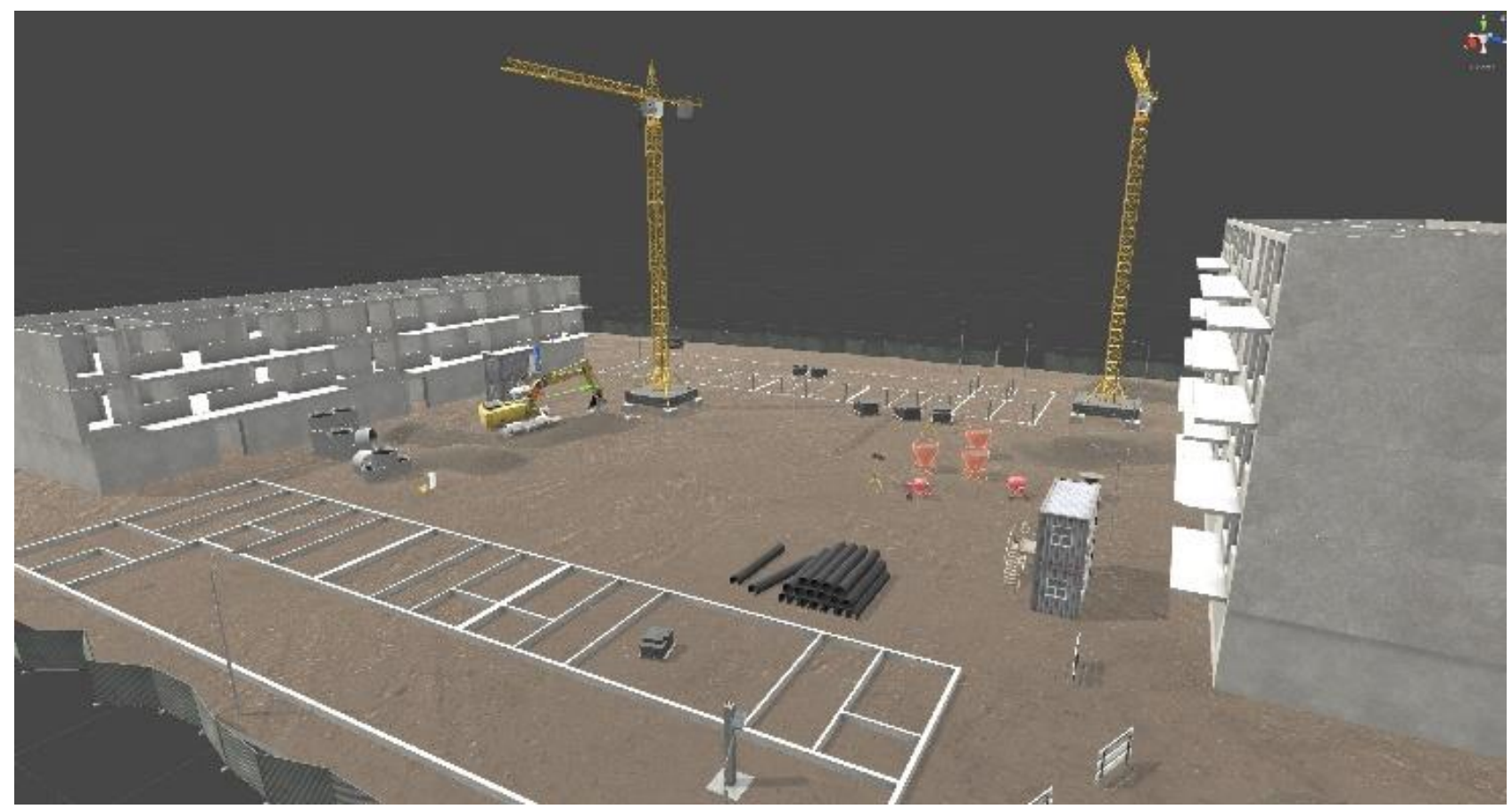

Fig. 1. Visualization of the construction site in the virtual environment of the tower crane simulator

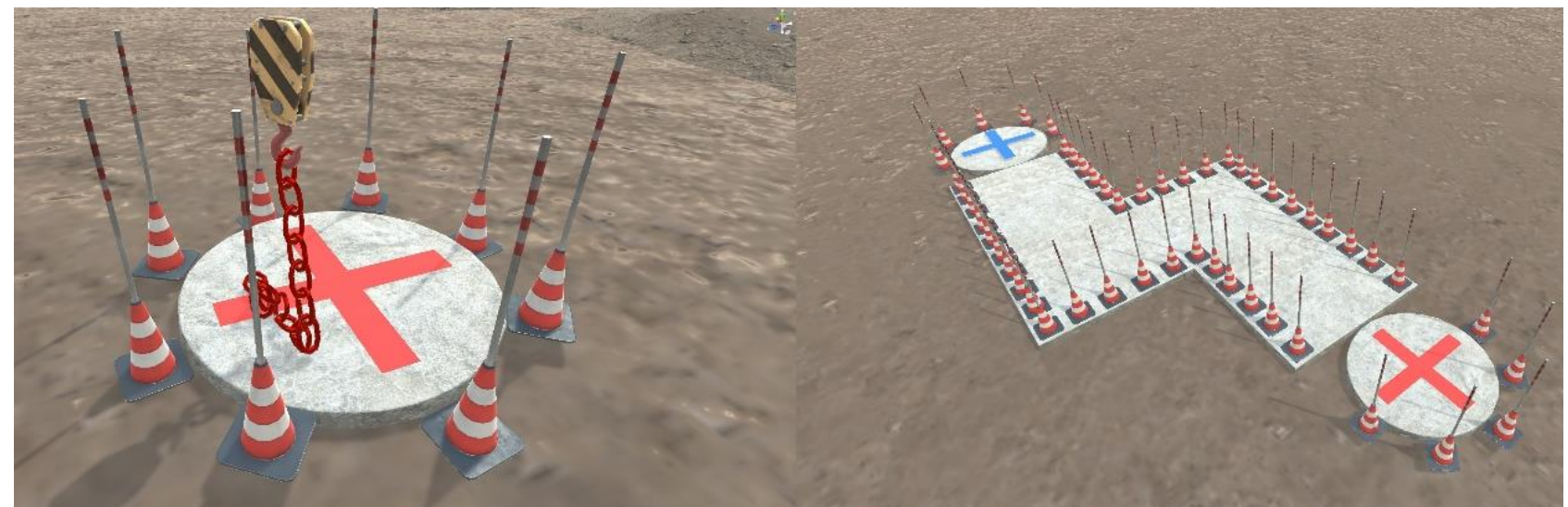

Fig. 2. Visualization of the manoeuvring area for training tasks implemented in the simulation

Simulation of the environment provides the opportunity to choose atmospheric factors - such as wind strength and direction, cloud cover or rainfall - and time of the day. The crane performance characteristics (rotational speed, speed and range of the truck, movement speed and rope length) are parameterized and can be adapted to the selected tower crane model.

The initial version of the available training scenarios (fig. 2) during simulation consists of three basic tasks:

- chain landing at a designated destination,

- transfer of a test load from the start to the final destination,

- moving the load along the designated path in two directions.

When performing tasks, the environment records the execution time and also counts and lists errors made. In the event of a critical error (causing potentially dangerous situation), the simulation is terminated with a negative result. One can implement additional scenarios when necessary. 


\section{Simulator design}

Mechanical components of the simulator can be divided into the following functional units: supporting structure, platform drive mechanism, operator's seat, computing unit, output devices (televisions and virtual reality goggles), input devices (controllers, sensors) and other electronics.

The supporting frame of the simulator (fig. 3 ) is made of durable aluminium profiles. Its structure ensures stable fixation of other elements and allows for corrections in their arrangement. The construction also includes a set of swivel wheels with a diameter of $20 \mathrm{~cm}$, which allow the platform to rotate and move the entire device.

Driving mechanism of the simulator (fig. 4) used to simulate the rotation of the tower crane, includes: a worm gear motor (with $1 \mathrm{~kW}$, output torque $114 \mathrm{Nm}$, maximum speed $30 \mathrm{rpm}$ and $24 \mathrm{~V}$ supply voltage), motor controller, power supply (230 V AC / $24 \mathrm{~V} \mathrm{DC}, 1.5 \mathrm{~kW}$ ), clutch, drive shaft, mounting bearings and cast iron drive wheel with rubber tire.

The entire system is attached to the supporting frame at its bottom with aluminium profiles.

The operator's seat (fig. 5) is a modified version of a standard seat used in construction machinery. It has adjustable cushioning, armrests and backrest tilt. The seat modification includes the aluminium profiles added for the installation of control devices, but this did not affect the feeling of the chair. The whole setup is mounted to a rotating platform, which is located below the chair. In addition, it is possible to change the position of the chair relative to the rotation centre, allowing more realistic operator placement.

Reception of virtual environment in the simulation is ensured by two output device systems (fig. 6), i.e. a set of monitors covering the crane operator's field of view and virtual reality goggles.

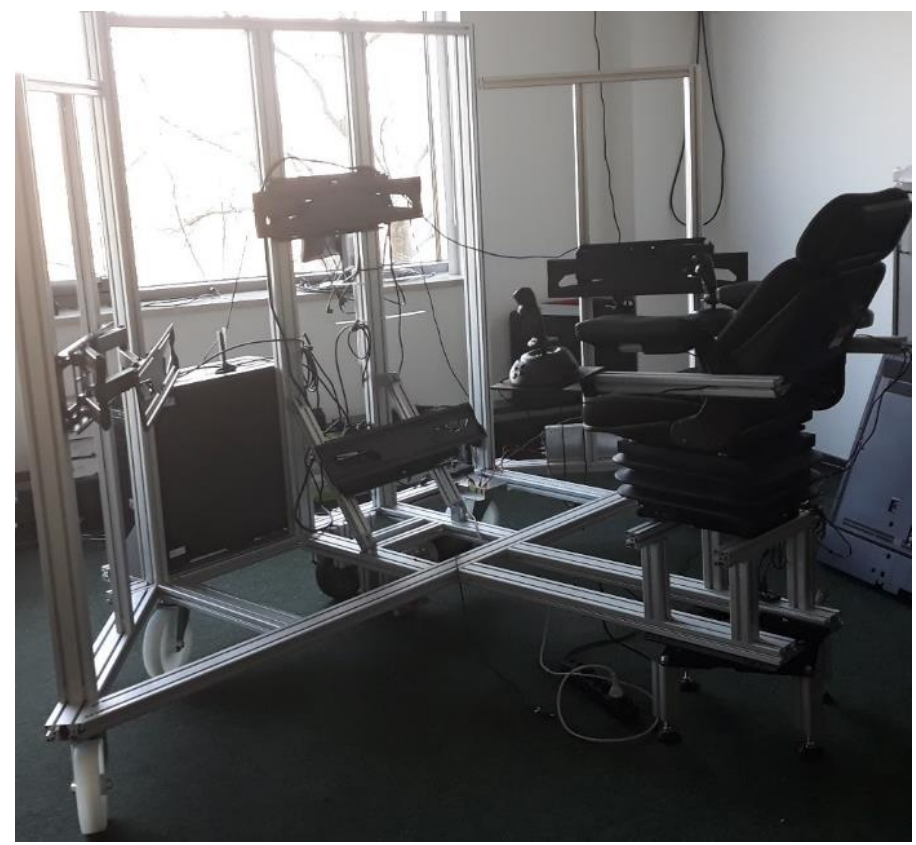

Fig. 3. Supporting structure of the crane simulator with the operator's seat and TV holders

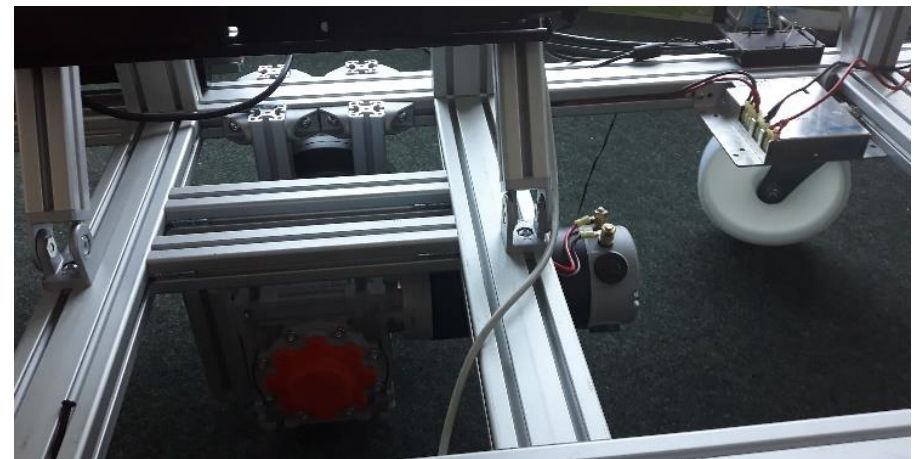

Fig. 4. Drive system of the rotating platform.

Picture presents the engine with worm gear, drive wheel with mounting and the engine controller attached to the frame 


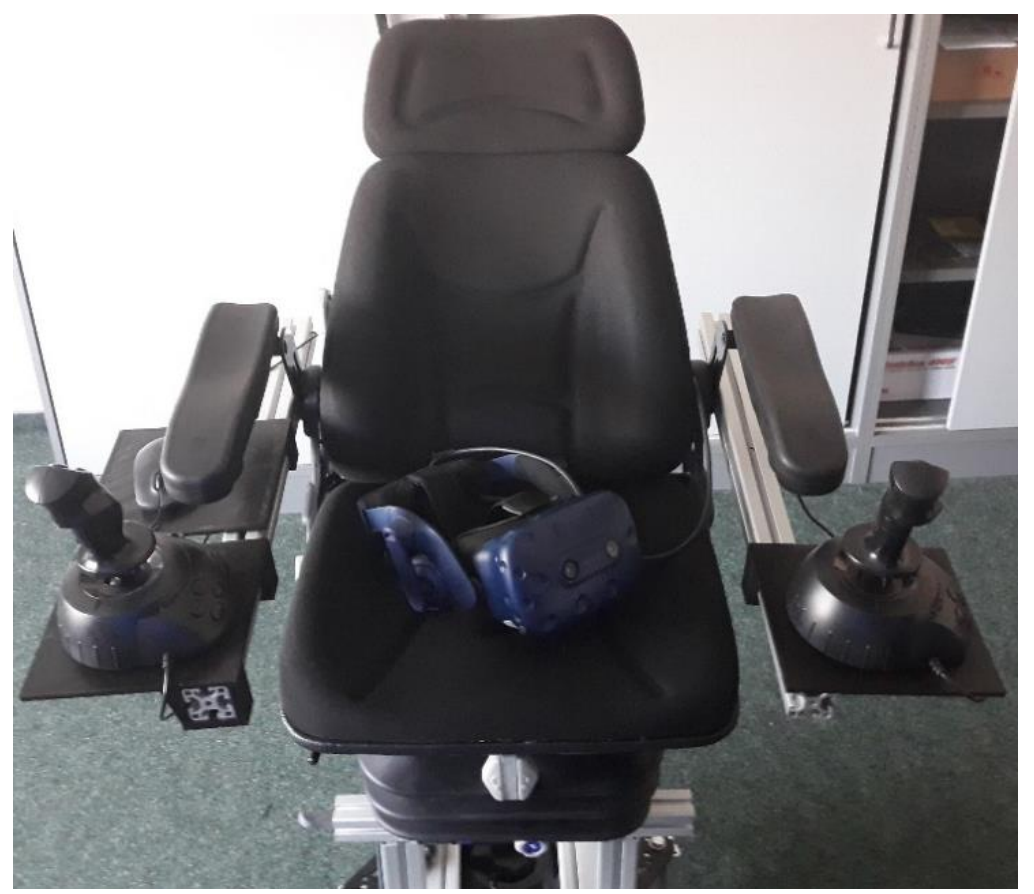

Fig. 5. Photo of the operator's seat with a set of manipulators and virtual reality goggles

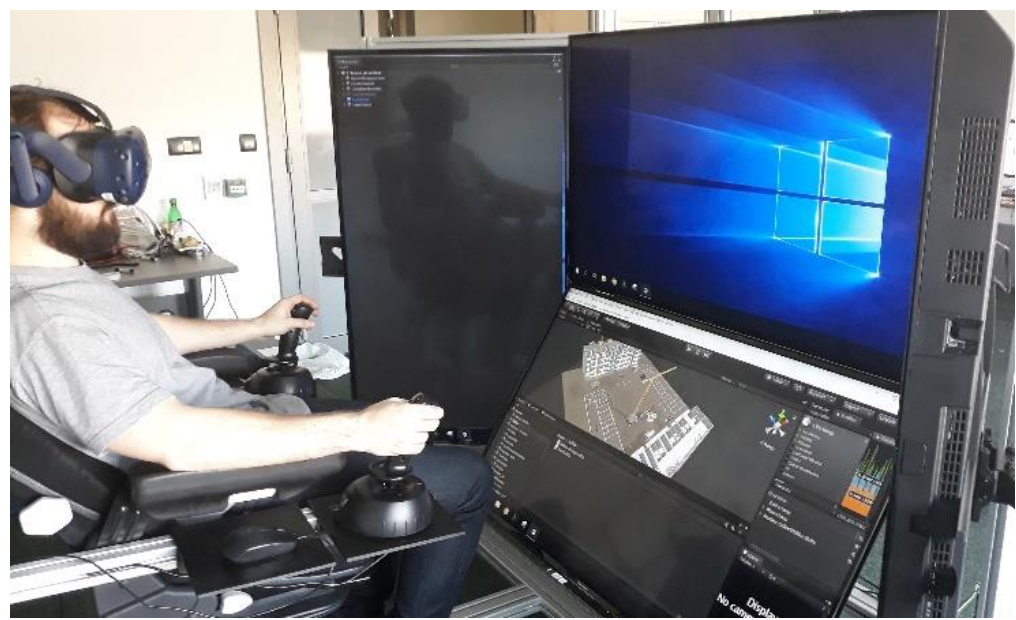

Fig. 6. Two image display systems: HTC Vive virtual reality goggles (on the operator's head) and a set of monitors covering the crane operator's field of view. The photo also shows the manipulators used to operate the crane

The design includes four 55-inch TV set in front of the operator, displaying the image in full HD resolution. Virtual reality system uses HTC Vive Pro goggles with base stations mounted in the frame that track its positions.

Contact with virtual environment is possible through a pair of joysticks imitating controllers used in real cranes. They allow a continuous movement with two degrees of freedom and eight buttons to operate various functions of the simulator. An angle position sensor, located on the base of the seat on a rotating platform, is used to control the rotation of the virtual crane. Rotational speed and position of the crane arm in the simulation are calculated based on measures of the simulator's platform rotation.

\section{User Interface}

An important aspect of any simulator is the way the user interacts with its elements. The level of immersion in the virtual environment and good matching of the simulation behaviour with a real machine increase the 
effectiveness of training, which is the basic value of such devices. For the proposed prototype tower crane simulator, several immersion elements were used: a television set covering the crane operator's field of view, virtual reality goggles, rotation of the simulator platform and the proper seat used in the crane's cabins. All these elements increases the operator's understanding of the conditions met in the real crane cabin, which strengthen the effectiveness of the device. Two image display systems will allow to perform comparative tests and select a better simulation method.

\section{Conclusions and further work}

The simulator design meets the assumed requirements. Operating parameters of the machine can be adjusted in order to resemble chosen tower crane model, allowing a user to better familiarize with its characteristics. Immersion elements increase the sense of presence in the virtual world, which positively affects the perception of the environment. The presented simulator should enrich the training process with the opportunity to practice operating a tower crane and learn its functionalities without any risk related to operation on a real tower crane. As a result, the overall qualifications of the operators should increase, which will directly translate into safety on construction sites.

Further work on the prototype will include the addition of another immersion element, which is a mechanical platform that imitates the tower crane tilt, as well as replacement of the operator's seat with newer one, that have built-in control panels. In addition, it is planned to conduct test runs with the participation of operators - both beginners and those with many years of experience, to evaluate the simulator's usability and adjust it to training requirements.

The publication has been based on the results of Phase IV of the National Programme "Safety and working conditions improvement", funded in the area of tasks related to services for the State by the Ministry of Labour and Social Policy. The Programme coordinator: Central Institute for Labour Protection - National Research Institute.

\section{REFERENCES}

[1] Health and Safety Laboratory. "Tower crane incidents worldwide". Health and Safety Executive, 2010.

[2] Zhou W., Zhao T., Liu W., Tang J. "Tower crane safety on construction sites: A complex sociotechnical system perspective". Safety Science. 109 (2018): 95-108.

[3] Walenc H., Lipiński T. „Koncepcja laboratoryjnej wersji symulatora żurawia wieżowego z platformą obrotową do szkolenia operatorów". Mechanik. 7 (2018): 594-596.

[4] Aneziris O., Papazoglou I., Mud M., Damen M., Kuiper J., Baksteen H., Ale B., Bellamy L., Hale A., Bloemhoff A., Post J., Oh J. “Towards risk assessment for crane activities”. Safety Science. 46, 6 (2008): 872-884.

[5] Solarz W., Tora G. „Sterowanie napędami żurawia wieżowego”. Transport Przemysłowy. 22, 4 (2005): $10-12$. 